\section{Postnatal corticosteroids to treat or prevent chronic lung disease in preterm infants}

\author{
Ann L Jefferies; Canadian Paediatric Society, Fetus and Newborn Committee
}

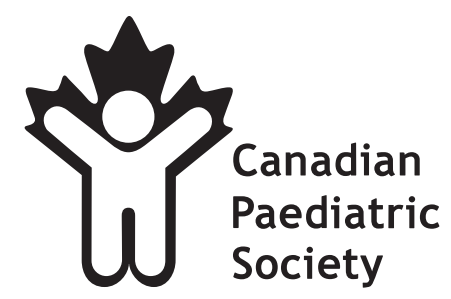

Full text at www.cps.ca Français en page 574

\begin{abstract}
Postnatal corticosteroids have been used for prevention and treatment of neonatal chronic lung disease (CLD) (also know as bronchopulmonary dysplasia), a significant cause of mortality and morbidity in preterm infants. As both dexamethasone and hydrocortisone administration within the first seven days of life is associated with an increased risk of cerebral palsy, early postnatal corticosteroid therapy is not recommended to prevent CLD. After seven days of life, dexamethasone has been shown to decrease the rate of CLD at 36 weeks' postmenstrual age with less impact on neurodevelopmental outcome. No trials have examined whether the benefits of corticosteroids outweigh the adverse effects for infants at high risk of, or with, severe CLD. While routine dexamethasone therapy of all ventilated infants is not recommended, clinicians may consider a short course of low-dose dexamethasone for individual infants at high risk of or with severe CLD. There is no evidence that hydrocortisone is an effective or safe alternative to dexamethasone and little evidence to support routine use of inhaled corticosteroids for prevention or treatment. Inhaled corticosteroids may be considered as an alternative to dexamethasone for treating individual infants with severe CLD. This revision replaces a statement published jointly with the American Academy of Pediatrics in 2002.
\end{abstract}

Key Words: Bronchopulmonary dysplasia; Chronic lung disease; Dexamethasone; Postnatal corticosteroids; Preterm infants

\title{
RECOMMENDATIONS
}

The strength of recommendations are based on the Canadian Task Force on Preventitive Health Care: <www.canadiantaskforce.ca>.

Based on available evidence:

1. Using postnatal corticosteroids - dexamethasone, hydrocortisone or inhaled corticosteroids - within the first seven days of life to prevent CLD is not recommended. (Grade A recommendation)

2. Administering high-dose dexamethasone $(0.5 \mathrm{mg} / \mathrm{kg} /$ day $)$ to prevent or treat CLD is not recommended. (Grade $A$ recommendation)

3. The routine use of low-dose dexamethasone $(0.15 \mathrm{mg} / \mathrm{kg} /$ day to $0.2 \mathrm{mg} / \mathrm{kg} /$ day $)$ for all infants who require assisted ventilation after seven days of age to prevent or treat CLD is not recommended. (Grade A recommendation)

4. Hydrocortisone is not recommended for treating CLD. (Grade A recommendation)

5. The routine use of inhaled corticosteroids to prevent CLD is not recommended. (Grade A recommendation)

6. It is unclear whether the benefits of late dexamethasone therapy outweigh the adverse effects for infants who are at high risk of CLD or for those with prolonged ventilator-dependence. If clinicians choose, after parental agreement, to treat an infant who is ventilatordependent, at risk of severe CLD or who has severe CLD, low-dose dexamethasone (initial dose $0.15 \mathrm{mg} / \mathrm{kg} / \mathrm{day}$ to $0.2 \mathrm{mg} / \mathrm{kg} / \mathrm{day}$ ) should be used in tapering doses over a short course (seven to 10 days). Inhaled corticosteroids may be considered as an alternative to dexamethasone, but the most effective dose and duration of therapy is not known. (Grade C recommendation)

7. Randomized trials are needed to investigate low-dose dexamethasone treatment regimes, the treatment of infants at high risk for CLD and the impact of inhaled corticosteroids for the management of infants with CLD. It is imperative that all trials include long-term neurodevelopmental follow-up.

ACKNOWLEDGEMENT: Special thanks to a past member of the CPS Fetus and Newborn Committee, Dr Haresh M Kirpalani, who helped draft this revision.

\section{CPS FETUS AND NEWBORN COMMITTEE}

Members: Ann L Jefferies MD (Chair); Thierry Lacaze-Masmonteil MD; Leigh Anne Newhook MD (Board Representative); Abraham Peliowski MD; S Todd Sorokan MD; Richard Stanwick MD (past Board Representative); Hilary EA Whyte MB

Liaisons: Michael S Dunn MD (past liaison, CPS Neonatal-Perinatal Medicine Section); Sandra Dunn RN, PhD (past liaison, Canadian Perinatal Programs Coalition); Andrée Gagnon MD, College of Family Physicians of Canada; Robert Gagnon MD, Society of Obstetricians and Gynaecologists of Canada; Juan Andrés León MD, Public Health Agency of Canada; Eugene H Ng MD, CPS Neonatal-Perinatal Medicine Section; Patricia A O'Flaherty MN MEd, Canadian Association of Neonatal Nurses; Lu-Ann Papile MD, Committee on Fetus and Newborn, American Academy of Pediatrics; Robin K Whyte MD (past member)

Principal author: Ann L Jefferies MD

The recommendations in this statement do not indicate an exclusive course of treatment or procedure to be followed. Variations, taking into account individual circumstances, may be appropriate. All Canadian Paediatric Society position statements and practice points are reviewed on a regular basis. Please consult the Position Statements section of the CPS website (www.cps.ca) for the full-text, current version. 